\title{
PENENTUAN PROGRAM DANA PENSIUN PADA GEREJA PROTESTAN MALUKU MENGGUNAKAN METODE INDIVIDUAL LEVEL PREMIUM
}

\author{
Lexy J. Sinay $^{1^{*}}$, Delvin S. Pattireuw ${ }^{2}$, A. Z. Wattimena ${ }^{3}$ \\ 1,2,3 Jurusan Matematika, Fakultas MIPA, Universitas Pattimura \\ Jln. Ir. M. Putuhena, Kampus Unpatti, Poka-Ambon, 97233, Indonesia \\ e-mail:1*lexyjz@gmail.com;2delvinstheynerpattireuw@gmail.com; \\ Corresponding Author *
}

\begin{abstract}
Abstrak
Tenaga kerja merupakan salah satu aset utama dalam pembangunan nasional. Pendeta, pemuka agama Kristen Protestan, merupakan tenaga kerja sekaligus profesi yang memegang peranan penting dalam membina karakter umat Kristen untukberiman dan bertaqwa, serta bermanfaat bagi bangsa dan negara. Gereja Protestan Maluku (GPM) sebagai suatu denominasi dan organisasi gereja memiliki manajemen keuangan dalam membiayai dana pensiun para pendetanya. Penelitian ini bertujuan untuk menentukan program dana pensiun para pendeta dalam organisasi Gereja Protestan Maluku menggunakan metode individual level premium, kemudian mengkomparasi hasil penghitungan tersebut dengan program dana pensiun yang dimiliki oleh Gereja Protestan Maluku. Hasil yang diperoleh adalah program dana pensiun menggunakan metode individual level premium lebih optimal dibandingkan program dana pensiun yang dikeluarkan oleh pihak Sinode GPM. Hal ini karena penghitungan nilai manfaat yang diperoleh setiap peserta menggunakan metode individual level premium sesuai dengan masa kerja, proporsi gaji akhir dan iuran yang dibayarkan oleh para pendeta, sedangkan penghitungan oleh pihak sinode tidak sesuai.
\end{abstract}

Kata Kunci : Dana Pensiun, Metode Individual Level Premium,Gereja Protestan Maluku, Pendeta

\section{DETERMINATION OF THE PENSION FUND PROGRAMS IN GEREJA PROTESTAN MALUKU USING INDIVIDUAL LEVEL PREMIUM METHOD}

\begin{abstract}
Labor is one of the main assets in national development. The pastor, the leader of Christianity, is both a workforce and a profession that plays an important role in fostering the character of Christians to be faithful and devoted, and beneficial to the nation and state. The Gereja Protestan Maluku (GPM) as a denomination and church organization has financial management in financing the pension funds of its pastors. This study aims to determine the pension fund program of priests in the Gereja Protestan Maluku using individual methods of premium level, then compare the results of the calculation with the pension fund program owned by the Gereja Protestan Maluku. The results obtained are pension fund programs using individual premium level methods that are more optimal than the pension fund programs issued by the Sinode Gereja Protestan Maluku, because the calculation of the benefit value obtained by each participant uses an individual method of premium level according to the period of employment, the proportion of the final salary and fees paid by the priests, while the calculation by the synod was not appropriate.
\end{abstract}

Keywords: Pension Fund, Individual Level Premium Method, Gereja Protestan Maluku, Pastor 


\section{PENDAHULUAN}

Tenaga kerja merupakan aset utama dalam pembangunan nasional. Sebagian besar masyarakat di Indonesia berlomba-lomba untuk bekerja dalam sebuah lembaga atau institusi baik itu berprofesi sebagai PNS, TNI, POLRI, pegawai BUMN, maupun sebagai karyawan swasta. Berbagai manfaat dapat diperoleh dalam profesi-profesi tersebut, yakni selain mendapat upah dan memperoleh fasilitas saat bekerja, manfaat lain yang dapat diperoleh adalah adanya jaminan asuransi pada saat usia produktif dan jaminan dana pension ketika memasuki usia lanjut.

Indonesia merupakan negara yang berdasarkan Ketuhanan Yang Maha Esa sehingga mengatur dan menjamin kehidupan semua umat beragama di Negara Indonesia. Tenaga kerja atau profesi yang berperan penting dalam mengatur dan membina karakter umat beragama adalah pemuka agama. Pemuka agama dalam Agama Kristen Protestan adalah pendeta. Profesi pendeta dibutuhkan untuk melayani umat Kristen dalam upaya membina karakter umat Kristen yang beriman dan bertaqwa kepada Tuhan serta berguna bagi bangsa dan negara. Umumnya, profesi tersebut tetap melaksanakan tugas walaupun memasuki usia pensiun seperti melayani dan berkhotbah di gereja. Tidak semua denominasi gereja di Indonesia memiliki sistem pembayaran upah dan pemberian dana pensiun kepada pendeta-pendeta yang sudah memasuki usia pensiun. Di Maluku, Gereja Protestan Maluku (GPM) melalui sinodenya memiliki sistem keuangan yang membayar upah pendeta-pendeta aktif dan juga memberi santunan pensiun kepada pendeta-pendeta yang sudah memasuki usia pensiun.

Pemberian dana pensiun untuk para pendeta yang sudah memasuki usia pensiun sudah dilakukan oleh GPM, namun pengaturan gaji pendeta dan pemberian dana pensiun pada GPM masih bersifat konvensional, belum memikirkan tentang tingkat suku bunga dan peluang investasi yang dapat menguntungkan GPM serta meningkatkan kesejahteraan para pendeta (baik yang aktif maupun yang sudah pensiun). Untuk itu, Sinode GPM diharapkan mampu menciptakan program pensiun yang bisa memberikan manfaat yang optimal bagi kesejahteraan pendeta dan pihak Sinode GPM.

Penelitian ini bertujuan untuk menghitung dana pensisun yang meliputi nilai manfaat, kewajiban aktuaria, dan iuran normal para pendeta di Sinode GPM. Penghitungan tersebut menggunakan Metode Individual Level Premium yakni menghitung nilai pensiun per individu pendeta pada sinode GPM. Hasil penghitungan tersebut akan dikomparasikan dengan penghitungan dana pensiun yang digunakan oleh Sinode GPM. Penelitian ini dibatasi dengan penggunaan asumsi bahwa tingkat kenaikan gaji dipengaruhi oleh masa kerja, sedangkan kebijakan pemerintah disumsikan tidak mempengaruhi penghitungan dana pensiun.

\section{METODE PENELITIAN}

Tipe penelitian dalam penelitian ini adalah studi kasus yaitu dengan menerapkan metode Individual Level Premium untuk merancangkan dana pensiun pendeta Sinode Gereja Protestan Maluku (GPM) Ambon.

\section{HASIL DAN PEMBAHASAN}

\subsection{Perhitungan Dana Pensiun Sinode GPM}

\section{Skala Gaji Sinode}

Skala gaji bagi pendeta berdasarkan golongan dan masa kerja, peningkatan gaji sebesar $10 \%$ dalam selang waktu dua tahun. Berikut adalah skala gaji untuk golongan III-B.

Tabel 1. Skala Gaji Golongan III-B

\begin{tabular}{|c|c|c|c|}
\hline \multicolumn{4}{|c|}{ SKALA GAJI -GOLONGAN III-B } \\
\hline \multirow{2}{*}{ Masa Kerja/Tahun } & Gaji/Bulan (Rp) & Gaji/Tahun (Rp) & \multirow{2}{*}{ Akumulasi Gaji } \\
\hline 0 & 1.778 .800 & 21.345 .600 & 21.345 .600 \\
\hline 1 & 1.778 .800 & 21.345 .600 & 42.691 .200 \\
\hline
\end{tabular}




\begin{tabular}{|c|c|c|c|}
\hline 2 & 1.826 .900 & 21.922 .800 & 64.614 .000 \\
\hline 3 & 1.826 .900 & 21.922 .800 & 86.536 .800 \\
\hline 4 & 1.876 .000 & 22.512 .000 & 109.048 .800 \\
\hline 5 & 1.876 .000 & 22.512 .000 & 131.560 .800 \\
\hline 6 & 1.926 .600 & 23.119 .200 & 154.680 .000 \\
\hline 7 & 1.926 .600 & 23.119 .200 & 177.799 .200 \\
\hline 8 & 1.978 .800 & 23.745 .600 & 201.544 .800 \\
\hline 9 & 1.978 .800 & 23.745 .600 & 225.290 .400 \\
\hline 10 & 2.032 .100 & 24.385 .200 & 249.675 .600 \\
\hline 11 & 2.032 .100 & 24.385 .200 & 274.060 .800 \\
\hline 12 & 2.087 .100 & 25.045 .200 & 299.106 .000 \\
\hline 13 & 2.087 .100 & 25.045 .200 & 324.151 .200 \\
\hline 14 & 2.143 .500 & 25.722 .000 & 349.873 .200 \\
\hline 15 & 2.143 .500 & 25.722 .000 & 375.595 .200 \\
\hline 16 & 2.201 .300 & 26.415 .600 & 402.010 .800 \\
\hline 17 & 2.201 .300 & 26.415 .600 & 428.426 .400 \\
\hline 18 & 2.260 .700 & 27.128 .400 & 455.554 .800 \\
\hline 19 & 2.260 .700 & 27.128 .400 & 482.683 .200 \\
\hline 20 & 2.321 .900 & 27.862 .800 & 510.546 .000 \\
\hline 21 & 2.321 .900 & 27.862 .800 & 538.408 .800 \\
\hline 22 & 2.384 .500 & 28.614 .000 & 567.022 .800 \\
\hline 23 & 2.384 .500 & 28.614 .000 & 595.636 .800 \\
\hline 24 & 2.448 .800 & 29.385 .600 & 625.022 .400 \\
\hline 25 & 2.448 .800 & 29.385 .600 & 654.408 .000 \\
\hline 26 & 2.514 .900 & 30.178 .800 & 684.586 .800 \\
\hline 27 & 2.514 .900 & 30.178 .800 & 714.765 .600 \\
\hline 28 & 2.582 .900 & 30.994 .800 & 745.760 .400 \\
\hline 29 & 2.582 .900 & 30.994 .800 & 776.755 .200 \\
\hline 30 & 2.652 .500 & 31.830 .000 & 808.585 .200 \\
\hline 31 & 2.652 .500 & 31.830 .000 & 840.415 .200 \\
\hline 32 & 2.724 .000 & 32.688 .000 & 873.103 .200 \\
\hline 33 & 2.724 .000 & 32.688 .000 & 905.791 .200 \\
\hline 34 & 2.797 .500 & 33.570 .000 & 939.361 .200 \\
\hline 35 & 2.797 .500 & 33.570 .000 & 972.931 .200 \\
\hline
\end{tabular}

\section{Manfaat pensiun}

Manfaat pensiun para pendeta disinode GPM Ambon dihitung $75 \%$ dari gaji pokok untuk masa kerja diatas 25 tahun, jika masa kerja dibawa 25 tahun, maka manfaat pensiun didapat dari $3 \%$ dikalikan dengan gaji pokok kemudian dikalikan dengan masa kerja misalnya pada data diambil 10 pendeta dengan 5 pendeta no 1 sampai 5 untuk jenis kelamin laki laki dan 5 pendeta untuk jenis kelamin perempuan. Sebagai contoh perhitungan diambil pendeta dengan no urut 1 jenis kelamin perempuan golongan III-B total masa kerja 33 tahun dan gaji pokok sekarang Rp 2.514.000.

$$
\begin{aligned}
& \mathrm{Br}=\text { Gaji pokok } * 12 * 75 \% * \\
& =\operatorname{Rp} 2.514 .000 * 12 * 75 \% \\
& =\operatorname{Rp} 22.634 .100
\end{aligned}
$$

Dengan cara yang sama dihitung untuk sampai pendeta No. 5.

Selanjutnya pendeta nomor 1 berjenis kelamin laki-laki golongan III-B dengan masa kerja 29 tahun dengan gaji pokok sekarang Rp 2.384.500.

$$
\begin{aligned}
& \mathrm{Br}=\text { Gaji pokok } * 12 * 75 \% * \\
& =\operatorname{Rp} 2.384 .500 * 12 * 75 \% \\
& =\operatorname{Rp} 26.100 .000
\end{aligned}
$$

Dengan cara yang sama dihitung sampai pendeta No. 5 . 


\section{Iuran Pesiun}

Iuran pensiun telah ditetapkan konstan sebanyak Rp. 100.000,- yang akan dipotong dari setiap gaji pokok pendeta. misalnya iuran untuk kedua pendeta diatas:

$$
\begin{aligned}
\text { Pdt 1: } \mathrm{NC} & =\operatorname{Rp} 100.000 * 12 * 33 \\
& =\operatorname{Rp} 39.600 .000 \\
\text { Pdt 2: } \mathrm{NC} & =\operatorname{Rp} 100.000 * 12 * 29 \\
& =\operatorname{Rp} 34.800 .000
\end{aligned}
$$

Selanjutnya untuk cara yang sama dihitung sampai pendeta No. 5.

Tabel 2. Tabel Perhitugan Sinode GPM Ambon.

\begin{tabular}{|ccccccc|}
\hline Nama & P/L & $\begin{array}{c}\text { Golongan } \\
\text { Terakhir }\end{array}$ & $\begin{array}{c}\text { Masa kerja } \\
\text { Sekarang }\end{array}$ & $\begin{array}{c}\text { Total } \\
\text { masa } \\
\text { kerja }\end{array}$ & $\boldsymbol{r}_{(\boldsymbol{N C})_{\boldsymbol{x}}}$ & $\boldsymbol{B}_{\boldsymbol{x}}$ \\
\hline Pdt. 1 & $\mathrm{P}$ & III/b & 26 & 33 & 39.600 .000 & 22.634 .100 \\
\hline Pdt. 2 & $\mathrm{P}$ & III/b & 6 & 13 & 15.600 .000 & 9.016 .488 \\
\hline Pdt. 3 & P & III/b & 7 & 26 & 31.200 .000 & 17.339 .400 \\
\hline Pdt. 4 & P & III/b & 16 & 29 & 34.800 .000 & 19.811 .700 \\
\hline Pdt. 5 & P & III/b & 7 & 27 & 32.400 .000 & 17.339 .400 \\
\hline Pdt. 6 & P & III/b & 7 & 26 & 31.200 .000 & 17.339 .400 \\
\hline Pdt. 7 & P & III/b & 7 & 22 & 26.400 .000 & 17.339 .400 \\
\hline Pdt. 8 & P & III/b & 13 & 30 & 36.000 .000 & 18.783 .900 \\
\hline Pdt. 9 & P & III/c & 23 & 32 & 38.400 .000 & 22.320 .900 \\
\hline Pdt. 10 & P & III/c & 15 & 24 & 28.800 .000 & 19.262 .016 \\
\hline Pdt. 1 & L & III/b & 22 & 29 & 34.800 .000 & 26.100 .000 \\
\hline Pdt. 2 & L & III/b & 13 & 26 & 31.200 .000 & 23.400 .000 \\
\hline Pdt. 3 & L & III/b & 7 & 28 & 33.600 .000 & 25.200 .000 \\
\hline Pdt. 4 & L & III/b & 16 & 27 & 32.400 .000 & 24.300 .000 \\
\hline Pdt. 5 & L & III/b & 25 & 31 & 37.200 .000 & 27.900 .000 \\
\hline Pdt. 6 & L & III/c & 25 & 31 & 37.200 .000 & 27.900 .000 \\
\hline Pdt. 7 & L & III/c & 23 & 31 & 37.200 .000 & 27.900 .000 \\
\hline Pdt. 8 & L & III/c & 17 & 29 & 34.800 .000 & 26.100 .000 \\
\hline Pdt. 9 & L & III/c & 11 & 25 & 30.000 .000 & 22.500 .000 \\
\hline Pdt. 10 & L & III/c & 26 & 31 & 37.200 .000 & 27.900 .000 \\
\hline
\end{tabular}

\subsection{Tabel Mortalita GAM 1971}

Dalam pengelolaan program pensiun, perusahaan menggunakan tabel Mortalita sebagai acuan untuk menghitung anuitas, iuran dan menyusun tabel pelayanan (service table). Dalam penelitian ini untuk menentukan manfaat pensiun dengan metode Individual Level Premium. Peneliti menggunakan tabel mortalita GAM 1971 dengan asumsi: 125\% untuk jenis kelamin laki-laki dan 80\% untuk jenis kelamin perempuan.

$x=$ usia peserta program pensiun periode saat ini (tanggal penghitungan aktuaria).

Usia terkecil peserta pada studi kasus adalah 23 tahun.

$$
x=23
$$

$q_{x}=$ peluang kematian peserta saat berusia $x$.

Berdasarkan tabel Gam Yang digunakan peluang kematian yang diseleksi untuk jenis kelamin perempuran dan laki-laki yaitu:

$p_{x}=$ peluang hidup peserta

$$
q_{x}=23: 58
$$

$q_{23}$ dalam tabel mortalita untuk jenis kelamin laki-laki $=0,000566$

$$
\begin{aligned}
p_{23}= & 1-q_{23 x} \\
& =1-0,000566 \\
& =0,999434
\end{aligned}
$$


$q_{23}$ dalam tabel mortalita untuk jenis kelamin perempuan $=0,000309$

$$
\begin{aligned}
p_{23}= & 1-q_{23 x} \\
& =1-0,000309 \\
& =0,999691
\end{aligned}
$$

$l_{x}^{(T)}=$ banyaknya peserta yang berusia tepat $x$ tahun, dan masih tetap bekerja.

$l_{23}^{(T)}$ untuk jenis kelamin laki laki yaitu: 1000

$$
\begin{aligned}
l_{24}^{(T)}= & l_{23}^{(T)}-q_{24} \\
& =1000-0,000591 \\
& =999,4340
\end{aligned}
$$

$l_{23}^{(T)}$ untuk jenis kelamin perempuan yaitu: 1000

$$
\begin{aligned}
l_{24}^{(T)}= & l_{23}^{(T)}-q_{24} \\
& =1000-0,000327 \\
& =999,999673
\end{aligned}
$$

\subsection{Tabel Pelayanan (Service Tabel).}

Untuk memudahkan perhitungan dalam penentuan dana pensiun harus menyusun tabel pelayanan (Service Tabel). Dalam penelitian ini service tabel disusun menggunakan tabel Mortalita GAM 1971.

$x=$ usia peserta program pensiun periode saat ini (tanggal penghitungan aktuaria).

Usia terkecil peserta pada studi kasus adalah 23 tahun.

$$
x=23
$$

$l_{x}^{(T)}=$ banyaknya peserta yang berusia tepat $x$ tahun, dan masih tetap bekerja.

$v_{x}^{n}=$ suku bunga ditetapkan oleh BI rate untuk tahun sekarang yaitu $i=4,5 \%$

$$
\begin{aligned}
v_{24}^{1}= & \left(\frac{1}{1+i}\right)^{1} \\
& =\left(\frac{1}{1+4,5 \%}\right)^{1} \\
& =0,9569
\end{aligned}
$$

$D_{x}^{(T)}=$ jumlah peserta yang meninggal dalam retang waktu $(\mathrm{x}+1)$

$D_{x}^{(T)}$ untuk jenis kelamin laki-laki yaitu:

$$
D_{x}^{(T)}=v_{x}^{n} * l_{x}^{(T)}
$$

$D_{x}^{(T)}$ untuk jenis kelamin perempuan yaitu:

$$
\begin{aligned}
D_{x: 24}^{(T)}= & v_{x: 24}^{n} * l_{x: 24}^{(T)} \\
& =0,9569 * 999,4340 \\
& =956,3962
\end{aligned}
$$

$$
\begin{aligned}
D_{x: 24}^{(T)}= & v_{x: 24}^{n} * l_{x: 24}^{(T)} \\
& =0,9569 * 999,6730 \\
& =956,6249
\end{aligned}
$$

$N_{x}^{(T)}=$ jumlah peserta pada tahun $x$

$N_{x}^{(T)}$ untuk jenis kelamin laki-laki yaitu:

$$
\begin{gathered}
N_{23}^{(T)}=\sum_{x=23}^{x=58} D_{x}^{(T)} \\
N_{23}^{(T)}=\sum_{x=23}^{x=58}(1000+956,3262+914,6708+\cdots \ldots+192,7782) \\
N_{23}^{(T)}=18145,7983
\end{gathered}
$$

$N_{x}^{(T)}$ untuk jenis kelamin perempuan yaitu: 


$$
\begin{gathered}
N_{23}^{(T)}=\sum_{x=23}^{x=58} D_{x}^{(T)} \\
N_{23}^{(T)}=\sum_{x=23}^{x=58}(1000+956,6249+915,4122+\cdots \ldots+192,7782) \\
N_{23}^{(T)}=18442,990
\end{gathered}
$$

${ }_{58-x} P_{x}^{(r)}=$ peluang peserta berusia $\mathrm{x}-1$ akan tetap hidup sampai memasuki usia pensiun (58 tahun). Yang dihitung menggunakan rumus:

Untuk jenis kelamin laki-laki:

$$
{ }_{r} P_{x}^{(T)}=\frac{l_{58}^{(T)}}{l_{x}^{(T)}}
$$

$$
\begin{gathered}
x=23 \\
{ }_{58} P_{23}^{(T)}=\frac{l_{58}^{(T)}}{l_{23}^{(T)}} \\
=\frac{899,7631}{1000} \\
=0,8997631
\end{gathered}
$$

Untuk jenis kelamin perempuan:

$$
\begin{gathered}
x=23 \\
{ }_{58} P_{23}^{(T)}=\frac{l_{58}^{(T)}}{l_{23}^{(T)}} \\
=\frac{955,612000}{1000} \\
=0,995612
\end{gathered}
$$

Hasil perhitungan tabel pelayanan (service table) jenis kelamin laki-laki dan perempuan untuk usia selanjutnya dapat dilihat pada lampiran.

\subsection{Perhitungan Aktuaria}

Untuk mewakili perhitungan aktuaria peneliti akan memakai data pada pendeta no. 1 untuk jenis kelamin laki-laki.

\section{Perhitungan Manfaat Pensiun}

Banyaknya manfaat pensiun yang akan didapatkan oleh seorang pendeta setiap tahunnya dipengaruhi oleh banyaknya gaji pendeta selama bekerja. Maka besarnya gaji pendeta yang harus disiapkan untuk dana pensiun adalah akumulasi gaji selama bekerja berdasarkan skala gaji yang telah ditetapkan. Skala gaji pendeta disusun berdasarkan golongan, dan masa kerja. Untuk skala gaji dan akumulasi gaji bisa dilihat pada lampiran.

Sebagai contoh perhitungan akan diambil skala gaji pada golongan III-b.

Contoh Perhitungan. Golongan III-B untuk jenis kelamin laki-laki

Diketahui data Usia masuk $(y=0)$, usia pensiun, $(r=58)$, usia sekarang massa kerja sampai pensiun (35), gaji pokok awal Rp.1.778.800 gaji pokok sampai pensiun Rp. 2.797.500

1. Menghitung nilai akumulasi dari gaji awal.

Akumulasi dengan gaji awal sebanyak Rp. 1.778.800 untuk golongan III-B sesuai dengan skala gaji dengan persamaan. Adalah:

Gaji untuk tahun pertama adalah:

$$
s_{o}=1.778 .800
$$

$$
\begin{aligned}
& s_{1}=1.778 .800 \times 12 \\
& =21.345 .600
\end{aligned}
$$

Gaji untuk tahun kedua adalah: 


$$
\begin{aligned}
& s_{2}=1.778 .800 \times 12 \\
& =21.345 .600
\end{aligned}
$$

Gaji untuk tahun ketiga adalah:

$$
\begin{aligned}
s_{3} & =1.826 .900 \times 12 \\
& =21.922 .800
\end{aligned}
$$

Selanjutnya untuk usia pensiun dengan masa kerja sudah 35 tahun adalah:

$$
\begin{aligned}
& s_{r}=2.797 .500 \times 12 \\
& =33.570 .000
\end{aligned}
$$

Selanjutnya untuk akumulasi gaji dari awal masuk sampai usia pensiun sesuai masa kerja sesuai dengan persamaan berikut:

$$
S_{r}=\sum_{t}^{r-1} s_{t}
$$

Akumulasi gaji untuk tahun pensiun dengan masa kerja akhir 35 tahun adalah:

$$
\begin{aligned}
S_{31}= & \sum_{t=27}^{r-1} 21.345 .600+21.922 .800+\cdots+33.570 .000 \\
& =972.931 .200
\end{aligned}
$$

Perhitungan akumulasi gaji untuk golongan yang lain bisa dilihat pada lampiran.

2. Menghitung proporsi gaji yang dialokasikan untuk manfaat pensiun.

Setelah menghitung akumulasi gaji awal selama bekerja, selanjutnya dihitung banyaknya proporsi gaji (k) yang dialokasikan untuk manfaat pensiun. Proporsi gaji yang ditetapakan oleh BI Rate adalah $(k=2,5 \%)$. sesuai dengan persamaan adalah:

$$
B_{r}=k s_{x}
$$

Proporsi gaji untuk Golongan III-B untuk masa kerja saat awal tahun sesuai perhitungan diatas adalah:

$$
\begin{aligned}
B_{r} & =2,5 \% \times 21.345 .600 \\
& =533.640
\end{aligned}
$$

Proporsi gaji untuk pendeta untuk golongan III-B untuk usia pensiun dengan masa kerja 35 tahun sesuai perhitungan diatas adalah:

$$
\begin{aligned}
B_{r} & =2,5 \% \times 972.931 .200 \\
& =24.323 .280
\end{aligned}
$$

Proporsi gaji akan meningkat sesuai dengan tingkat kenaikan gaji selama bekerja.

\subsection{Menghitung Iuran Pensiun}

Menghitung besar iuran dengan metode Individual Level Premium.

Banyaknya iuran untuk golongan III-B untuk usia awal dengan proporsi gaji menggunakan metode Individual Level Premium sesuai dengan persamaan adalah:

Iuran untuk awal masa kerja adalah:

Diketahui: $B_{r}=533.640$

$$
\operatorname{ILPr}(N C)_{x}=B_{r} \ddot{a}_{r}\left(\frac{D_{r}^{(T)}}{N_{x}^{(T)}-N_{r}^{(T)}}\right)
$$

$$
\begin{aligned}
& a_{r}=1, \quad D_{r}=192,7782393694, \quad N_{r}=192,7782393694 \\
& N_{x}=18145,7982716016 \\
& =14.175 .570 \times 1 \times\left(\frac{192,7782393694}{18145,7982716016-192,7782393694}\right) \\
& =5.730,1879835
\end{aligned}
$$


Banyakanya iuran diawal tahun memang berjumlah sedikit tetapi akan naik secara signifikan untuk tahun-tahun berikutnya sesuai tingkat kenaikan gaji. Saat masuk usia pensiun peserta sudah tidak lagi membayarkan iuran karena tidak lagi bekeja. Maka akan dihitung iuran sebelum masa kerjanya berakhir.

Diketahui:

$$
\operatorname{ILPr}(N C)_{x}=B_{r} \ddot{a}_{r}\left(\frac{D_{r}^{(T)}}{N_{x}^{(T)}-N_{r}^{(T)}}\right)
$$

$B_{r}=23.484 .030, a_{r}=1, D_{r}=192,7782393694, \quad N_{r}=192,7782393694$, $N_{x}=396,274397441404$

$$
\begin{aligned}
= & 23.484 .030 \times 1 \times\left(\frac{192,7782393694}{396,274397441404-192,7782393694}\right) \\
= & 22.247 .151,9835693
\end{aligned}
$$

Jadi banyaknya iuran pensiun selama masa kerja sampai memasuki usia pensiun dengan total masa kerja 34 tahun adalah sebanyak Rp. 22.247.151,9835693.

\subsection{Perhitungan Kewajiban Aktuaria.}

Kewajiban aktuaria yang dihitung menggunakan metode Individual Level Premium untuk golongan III-B sesuai dengan persamaan adalah sebanyak:

Diketahui:

$$
I_{L P}(A L)_{x}=\operatorname{ILPr}(N C)_{r}\left(\frac{N_{x}^{(T)}-D_{r}^{(T)}}{D_{x}^{(T)}}\right)
$$

$$
\begin{aligned}
\operatorname{ILPr}(N C)_{r} & =5.730,1879835 . D_{x}^{(T)}=1000 \\
I L P^{r}(A L)_{x} & =5.730,18 \times\left(\frac{18145,798271-192,7782393}{1000}\right) \\
& =102.874,1796571
\end{aligned}
$$

Kewajiban aktuaria atau dana cadangan untuk tahun pertama adalah sebanyak Rp: 102.874,1796571

Kewajiban akuaria satu tahun terakhir sebelum masa kerja berakhir adalah sebanyak: Diktahui:

$$
\begin{aligned}
&\left.\operatorname{ILPr}_{(N C}\right)_{r}=22.247 .151,9835693 ; \quad D_{x}^{(T)}=203,4961580719571 \\
& I L P^{r}(A L)_{x}=22.247 .151,98 \times\left(\frac{18145,798271-192,7782393}{203,4961580719571}\right) \\
&= 22.247 .151,9835693
\end{aligned}
$$

Jadi kewajiban aktuaria untuk golongan III-B dengan masa kerja 34 tahun sebelum berakhirya masa kerja adalah Rp.22.247.151,9835693.

Berdasarkan tabel perhitungan untuk golongan III-B bisa dilihat bawa untuk manfaat pensiun. iuran. Dan kewajiban aktuaria akan mengalami peningkatan setiap tahun sesuai dengan peningkatan gaji . Pada tabel juga memperlihatkan bahwa ketika masa kerja mencapai masa pensiun maka peserta tidak lagi membayarkan iuran, sedangkan nilai kewajiban aktuaria sebelum masuk masa pensiun akan sama dengan nilai iuran pensiun. Dan setelah pensiun nilai kewajiban aktuaria akan sama dengan nilai manfat pensiun yang akan didapatkan.

\subsection{Perbandingan Manfaat Pensiun}

Untuk membandingkan manfaat dan iuran pensiun akan digunakan hasil perhitungan manfaat untuk 20 pendeta pada tabel 3 untuk metode Individual Level Premium. 
Tabel 3. Perbandingan Manfaat pensiun Sinode GPM dan Metode Individual Level Premium.

\begin{tabular}{|ccccccc|}
\hline Nama & P/L & $\begin{array}{c}\text { Golongan } \\
\text { Terakhir }\end{array}$ & $\begin{array}{c}\text { Masa kerja } \\
\text { Sekarang }\end{array}$ & $\begin{array}{c}\text { Total masa } \\
\text { kerja }\end{array}$ & $\boldsymbol{B}_{\boldsymbol{r}}$ & $\boldsymbol{I L P}_{\boldsymbol{r}} \boldsymbol{B}$ \\
\hline Pdt. 1 & P & III/b & 26 & 33 & 22.634 .100 & $22.644 .780,000$ \\
\hline Pdt. 2 & P & III/b & 6 & 13 & 9.016 .488 & $10.050 .270,000$ \\
\hline Pdt. 3 & P & III/b & 7 & 26 & 17.339 .400 & $17.114 .670,000$ \\
\hline Pdt. 4 & P & III/b & 16 & 29 & 19.811 .700 & $12.067 .080,000$ \\
\hline Pdt. 5 & P & III/b & 7 & 27 & 17.339 .400 & $17.114 .670,000$ \\
\hline Pdt. 6 & P & III/b & 7 & 26 & 17.339 .400 & $17.869 .140,000$ \\
\hline Pdt. 7 & P & III/b & 7 & 22 & 17.339 .400 & $14.175 .570,000$ \\
\hline Pdt. 8 & P & III/b & 13 & 30 & 18.783 .900 & $20.214 .630,000$ \\
\hline Pdt. 9 & P & III/c & 23 & 32 & 22.320 .900 & $22.702 .800,000$ \\
\hline Pdt. 10 & P & III/c & 15 & 24 & 19.262 .016 & $16.252 .110,000$ \\
\hline Pdt. 1 & L & III/b & 22 & 29 & 26.100 .000 & $19.418 .880,00$ \\
\hline Pdt. 2 & L & III/b & 13 & 26 & 23.400 .000 & $17.114 .670,00$ \\
\hline Pdt. 3 & L & III/b & 7 & 28 & 25.200 .000 & $18.644 .010,00$ \\
\hline Pdt. 4 & L & III/b & 16 & 27 & 24.300 .000 & $17.869 .140,00$ \\
\hline Pdt. 5 & L & III/b & 25 & 31 & 27.900 .000 & $21.010 .380,00$ \\
\hline Pdt. 6 & L & III/c & 25 & 31 & 27.900 .000 & $21.852 .780,00$ \\
\hline Pdt. 7 & L & III/c & 23 & 25 & 27.900 .000 & $21.852 .780,00$ \\
\hline Pdt. 8 & L & III/c & 17 & 26.100 .000 & $20.197 .500,00$ \\
\hline Pdt. 9 & L & III/c & 11 & 26.500 .000 & $17.016 .180,00$ \\
\hline Pdt. 10 & L & III/c & 26 & 27.900 .000 & $21.852 .780,00$ \\
\hline
\end{tabular}

Berdasarkan tabel perbandingan terlihat bahwa manfaat yang dihitung oleh metode Individual Level Premium berbeda dengan perhitungan sinode GPM. karena proporsi gaji yang dipakai oleh sinode GPM lebih besar dan tidak sesuai dengan penentapan BI rate. Manfaat iuran yang terkumpul sampai masuk pensiun juga sangat besar dan tidak sebanding dengan jumlah manfaat yang diperoleh ole peserta sehinnga peserta akan mengalami kerugian.

\section{KESIMPULAN}

Berdasarkan hasil dan pembahasan yang telah diuraikan maka disimpulkan bahwa:

1. Perlu diperhatikan konsistensi penggunaan asumsi aktuaria dalam menentukan program dana pensiun, seperti tabel mortalita, proporsi gaji, tingkat suku bunga, dan tanggal penghitungan.

2. Hasil penghitungan dana pensiun para pendeta GPM menggunakan metode Individual Level Premium menunjukkan bahwa manfaat yang didapatkan oleh peserta sesuai dengan masa kerja, proporsi gaji akhir dan iuran yang dibayarkan oleh para pendeta. Selain itu, kewajiban aktuaria menggunakan metode Individual Level Premium bernilai sama dengan iuran yang dikumpulkan peserta selama bekerja,dan iuran yang dikumpulkan sama besar dengan nilai manfaat pensiun yang digunakan. Sehingga, program dana pensiunyang dihasilkan oleh metode Individual Level Premium lebih optimal dibandingkan program dana pensiun oleh pihak Sinode GPM. Program dana pensiun berdasarkan penghitungan pihak GPM tidak optimal karena dana pensiun yang diterima tidak sebanding dengan jumlah iuran yang dibayarkan selama bekerja, yakni pembayaran iurannya terlalu besar dan tidak sesuai dengan nilai manfaat yang diterima oleh peserta. 


\section{DAFTAR PUSTAKA}

[1]. Anita, Yuli., Penghitungan Manfaat Dan Iuran Peserta Program Dana Pensiun Dengan Metode Projected Unit Credit Dan Individual Level Premium. Pdf Skripsi., 2016.

[2]. N. L. Bowers, et. al., Actuarial Mathematics. Schaumburg (DE): The Society of Actuaries., 1997.

[3]. Farrimond, William \& Mayer, Duane L., Actuarial Cost Methods. Arlington: American Society of Pension Actuaries., 1999.

[4]. Promislow, S. David., Fundamentals of Acturial Mathematics. $3^{\text {rd }}$. Ed. United Kingdom: John Wiley \& Son, Ltd., 2015.

[5]. Setiadi, A., Dana Pensiun Sebagai Badan Hukum, Bandung: PT. Citra Aditya Bakti., 1995.

[6]. Winklevoss, Howard E, Pension Mathematics with Numerical Illustrations. Pension Research Council, The University Of Pennsylvania, Philadelphia., 1993. 